\title{
Making weld joints of dissimilar titanium alloys under low-temperature superplasticity conditions
}

\author{
M. Kh. Mukhametrakhimov \\ msia@mail.ru
}

Institute for Metals Superplasticity Problems RAS, 39 Khalturin St., 450001, Ufa, Russia

\begin{abstract}
Experimental studies of the solid-phase weldability of VT6 and VT14 industrial titanium alloys are carried out in the temperature range of low-temperature superplasticity (SP). In welding of dissimilar titanium alloys a significant reduction of the process temperature can be achieved by alloying with Mo. The use of an ultrafine grained (UFG) sheet of VT14 alloy, which is alloyed by Mo to stabilize the $\beta$-phase allows, enables to localize the deformation at the junction zone due to a significant difference between the flow stresses of the interlayer and sheets to weld. As a result, a structural laminate of sandwich type is obtained that contains two interfaces between the alloys VT6 and VT14. As the studies have shown, when approaching the junction zone from VT6 alloy, some small Mo content is detected and at the junction plane this content increases to the value typical for the base composition of VT14. Mechanical tests show that the pressure welding of sheet billets in different combinations results in a high level of mechanical properties and quality of the joints. For a comparative analysis, VT6 sheet billets without any intermediate sheet were joined under the same conditions. Mechanical tensile tests showed that there is a small delamination between the titanium sheets in the failure zone. A quality solid-phase joint in this case can be obtained by increasing the pressure and prolonging the time of process. It can be concluded, therefore, that obtaining high-quality solid-phase joints of dissimilar titanium alloys depends not only on the size of the intermediate sheet grains, but also on the chemical and phase composition of material in the joint zone.
\end{abstract}

Keywords: titanium alloys, solid phase joining, pressure welding, low temperature superplasticity, mechanical properties, shear strength, electron microscopy.

\section{Получение сварных соединений из разнородных титановых сплавов в условиях низкотемпературной сверхпластичности}

\author{
Мухаметрахимов М.X.
}

Институт проблем сверхпластичности металлов РАН, ул. Степана Халтурина 39, 450001, Уфа, Россия

Проведены экспериментальные исследования твердофазной свариваемости промышленных титановых сплавов ВТ6 с ВТ14 в температурном интервале проявления низкотемпературной сверхпластичности (СП). При сварке разнородных титановых сплавов можно значительно снизить температуру сварки давлением за счет использования сплавов легированных молибденом (Мо). Использование промежуточного листа ВТ14 с УМЗ структурой, легированного для стабилизации $\beta$-фазы Мо, позволяет локализовать деформацию в зоне соединения за счет существенной разницы между значениями напряжения течения материала прокладки и свариваемых листов. В результате соединения получается конструкционный слоистый материал типа «Сэндвич», в котором содержатся две зоны раздела металлов - между титановыми сплавами ВТ6 и ВТ14. Как показали исследования, с приближением к зоне соединения со стороны титанового сплава ВТ6 в материале появляется небольшое содержание Мо и при достижении линии соединения количество Мо достигает до уровня основного состава сплава ВТ14. Анализ результатов механических испытаний показал, что сварка давлением листовых заготовок в различных сочетаниях способствует достижению повышенных механических свойств и качества соединения. Для сравнительного анализа в тех же условиях соединяли листовые заготовки из титанового сплава ВТ6 без промежуточного листа. Механические испытания на растяжения показали, что наблюдается небольшое расслоение по сварному соединению между титановыми листами ВТ6. И только с увеличением дополнительного сварочного давления и времени выдержки в условиях низкотемпературной сверхпластичности возможно получить качественное соединение. Таким образом, можно сделать заключение, что получение качественного твердофазного соединения разнородных титановых сплавов определяется не только размером зерна промежуточного листа, но и химическим и фазовым составом в зоне сварных соединений.

Ключевые слова: титановые сплавы, твердофазное соединение, сварка давлением, низкотемпературная сверхпластичность, механические свойства, сдвиговая прочность, электронная микроскопия. 


\section{1. Введение}

Титановые сплавы широко распространены в машиностроении, авиационной промышленности, судостроении и других областях науки и техники вследствие высокой удельной прочности и коррозионной стойкости в большинстве агрессивных сред. Одним из самых распространенных и эффективных видов соединения титановых сплавов, позволяющих создавать сложные конструкции различного назначения, является сварка.

Соединение металлов и сплавов разного состава является перспективным направлением получения многофункциональных конструкций, у которых определенные зоны работают при разных условиях эксплуатации. В сварных конструкциях используются самые разнообразные титановые сплавы, их сочетания и биметаллы, и чем больше факторов влияет на сварное соединение, тем сложнее добиться необходимых свойств по всему сечению сварного соединения.

Основной проблемой соединений титановых сплавов является сложность получения равных прочности и пластичности в основном металле и сварном шве. Сварка титановых сплавов разных марок позволяет значительно снизить температуру сварки давлением за счет использования легированных Мо сплавов. Однако при создании таких композиций образуются несколько различных по структуре и свойствам зон, что затрудняет выбор последующей термической обработки.

Значительный объем экспериментальных результатов позволил надежно установить, что ускоренное образование ТФС происходит при деформационном соединении в состоянии сверхпластичности по сравнению с традиционной диффузионной сваркой. В частности, в работах $[1,2]$ на примере двухфазных титановых сплавов ВТ14 и ВТ8, легированных для стабилизации $\beta$-фазы молибденом (Мо), показана возможность достижения качественного соединения путем “залечивания” дефектов ТФС (микродефектов - пор и макродефектов - несплошностей) в процессе развития основного механизма СП деформации - зернограничного проскальзывания (ЗГП). Для сплава ВТ14 было выявлено, что вакуумный отжиг при оптимальной температуре СП деформации и соответствующем ей времени не оказывает заметного влияния на изменение протяженности дефектов и изменение прочности соединения.

Таким образом, для двухфазных титановых сплавов, легированных Мо, было экспериментально установлено $[1,2]$, что образование ТФС определяется механизмами СП течения, и в первую очередь, ЗГП. Однако, принимая во внимание легирование титанового сплава различающимися по своим свойствам $\beta$-стабилизаторами, в частности молибденом и ванадием, характеризующихся разными диффузионными параметрами [3], вероятно, вклад диффузионных и деформационных процессов в образование твердофазного соединения на различных этапах его формирования может меняться.

Непосредственное соединение титановых сплавов в различных сочетаниях при низких температурах, полученные в твердом состоянии - сваркой давлением, позволяет избежать или снизить вероятность расслое- ния и получить работоспособное изделие. Задачу уменьшения размера зерна в зоне сварного соединения самых различных композиций следует решать путем использования сплавов с ультрамелкозернистой (УМЗ) исходной структурой.

Целью работы являлось исследование твердофазной свариваемости промышленного титанового сплава ВТ6 с промежуточным листом из сплава ВТ14 с УМ3 структурой при пониженной температуре в температурном интервале проявления низкотемпературной СП.

\section{2. Материал и методика исследования}

Материалом для исследования был выбран промышленный двухфазный титановый микрозернистый (М3) сплав ВТ6 со средним размером зерен 2,3 мкм и ВТ14 с более мелком размером зерен $\sim 0,8$ мкм стандартного химического состава по ГОСТ 19807 -91. Химический состав приведен в таблице 1 .

Соединение листовых заготовок, собранных в пакет, выполняли в штамповом блоке, включающем силовые плиты и крепежные элементы [4], показаны на рис. 1.

Штамповый блок устанавливали в вакуумную печь СНВЭ-1,3.1/16-ИЗ-УХЛЧ.1. Полученную таким образом сборку стягивали силовыми элементами штампа, а затем устанавливали в вакуумную печь. Сварку в твердом состоянии осуществляли приложением газообразного аргона из штуцера через гибкую мембрану на свариваемые заготовки. Глубину вакуума в процессе эксперимента поддерживали не хуже $P=2,0 \times 10^{-3}$ Па. Качество твердофазного соединения (ТФС) оценивали по результатам механических испытаний на растяжение в соответствии с ГОСТ 6996-66 и на сдвиг по методике подробно представленной в [5], а также металлографических и фрак-

Табл. 1. Химический состав исследуемого сплава ВТ6 и ВТ14. Table 1. The chemical composition of the studied alloy VT6 and VT14.

\begin{tabular}{|c|c|c|c|c|c|c|c|c|c|c|}
\hline $\begin{array}{c}\text { Сплавы/вес.\% } \\
\text { Alloys/wt.\% }\end{array}$ & $\mathrm{Al}$ & $\mathrm{V}$ & $\mathrm{Mo}$ & $\mathrm{Fe}$ & $\mathrm{Si}$ & $\mathrm{O}$ & $\mathrm{C}$ & $\mathrm{N}$ & $\mathrm{H}$ & $\mathrm{Zr}$ \\
\hline $\begin{array}{c}\text { BT6 } \\
\text { VT6 }\end{array}$ & 6,5 & 5,1 & - & 0,3 & 0,1 & 0,2 & 0,1 & 0,05 & 0,015 & 0,3 \\
\hline $\begin{array}{c}\text { BT14 } \\
\text { VT14 }\end{array}$ & $\begin{array}{c}3.5- \\
6.3\end{array}$ & $\begin{array}{r}0.9- \\
1.9\end{array}$ & $\begin{array}{c}2.5- \\
3.8\end{array}$ & 0.3 & 0.15 & 0.15 & 0.1 & 0.05 & 0,015 & 0,3 \\
\hline
\end{tabular}

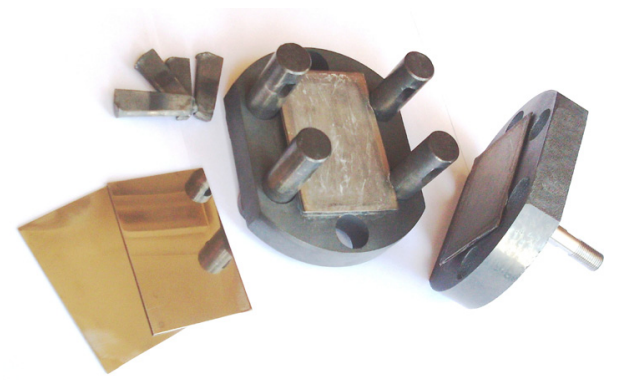

Рис. 1. Общий вид инструментальной оснастки для сварки давлением титановых листовых заготовок посредством давления газа через гибкую мембрану.

Fig. 1. General view of tools for pressure welding titanium sheets by gas pressure through a flexible membrane. 
тографических исследований с помощью сканирующего электронного микроскопа «TESCAN MIRA3 LMU» по относительной объемной доле (протяженности) пор в поперечном сечении зоны соединения. Относительную протяженность пор $\left(L_{p}\right)$ в зоне ТФС оценивали по формуле:

$$
L_{p}=L_{p i} / L_{o},
$$

где $L_{p i}-$ суммарная протяженность пор в плоскости шлифа, $L_{o}$ - длина исследуемого участка вдоль линии соединения в плоскости шлифа.

Химический анализ проводили с помощью приставки для энергодисперсионного анализа Oxford Instruments $\mathrm{X}$-act.

Средний размер зерен $d$ определяли методом секущих [6].

Для испытаний на сдвиг из двухслойных пакетов, сваренных между собой, вырезали специальные образцы, эскиз которых приведен на рис. 2.

Образцы на сдвиг вырезались таким образом, что условная линия ТФС располагалась в средней части образца параллельно оси растяжения.

Согласно методике [5] при толщине листовых заготовок $s=1,5$ мм ширину нахлеста в образцах $b$ выбирали равной 0,5 мм.

Испытания проводили на растяжение и на сдвиг при комнатной температуре на универсальном динамометре фирмы «Instron» модели 5982 по стандартной методике.

\section{3. Результаты и их обсуждение}

Эксперименты по сварке давлением проводили по двум схемам: В первом случае соединяли листовые заготовки из титанового сплава ВТ6 с промежуточным листом ВТ14 более мелком размером зерен $~ 0,8$ мкм. В результате соединения получается слоистый композит, в котором содержатся две зоны раздела металлов - между титановыми сплавами ВТ6 и ВТ14 (зона ВТ6+ВТ14) и (зона ВТ14+ ВТ6).

Во втором случае для сравнительного анализа соединяли листовые заготовки из титанового сплава ВТ6 между собой без промежуточного листа.

На рис. За представлена микроструктура сварных соединений титанового сплава ВТ6 через прокладку из УМЗ сплава ВТ14.

Как показали исследования (рис. 3b), с приближением к зоне соединения со стороны титанового сплава ВТ6 в материале появляется небольшое содержания Мо и при достижении линии соединения количество Мо достигает до уровня основного состава сплава ВТ14.

Анализ результатов механических испытаний на растяжения показал, что сварка давлением листовых заготовок в различных сочетаниях способствует достижению повышенных механических свойств и качества соединения (рис. 4а). Использование УМЗ прокладки позволяет локализовать деформацию в зоне соединения за счет существенной разницы между значениями напряжения течения материала прокладки и свариваемых заготовок (рис. 4b). Таким образом, появляется возможность управления процессом формирования соединения

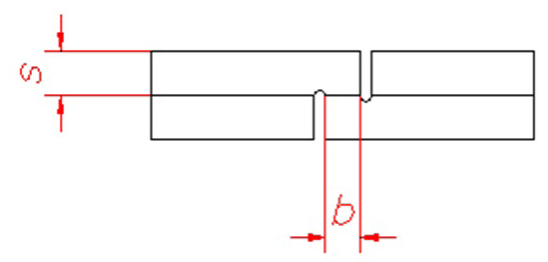

Рис. 2. Поперечное сечение образца для испытаний на сдвиг. Fig. 2. Cross section of the specimen ready to be shear-tested.

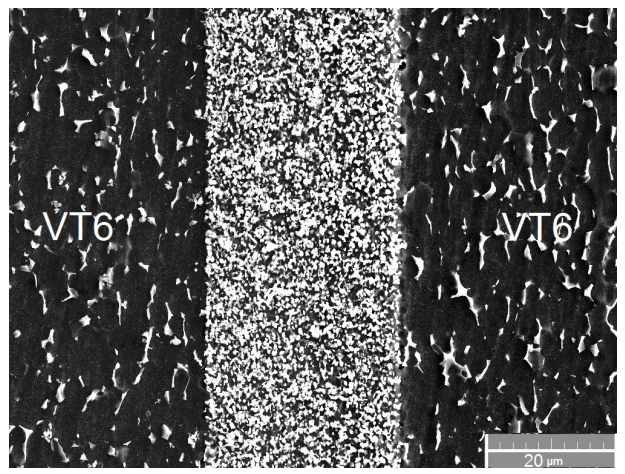

a

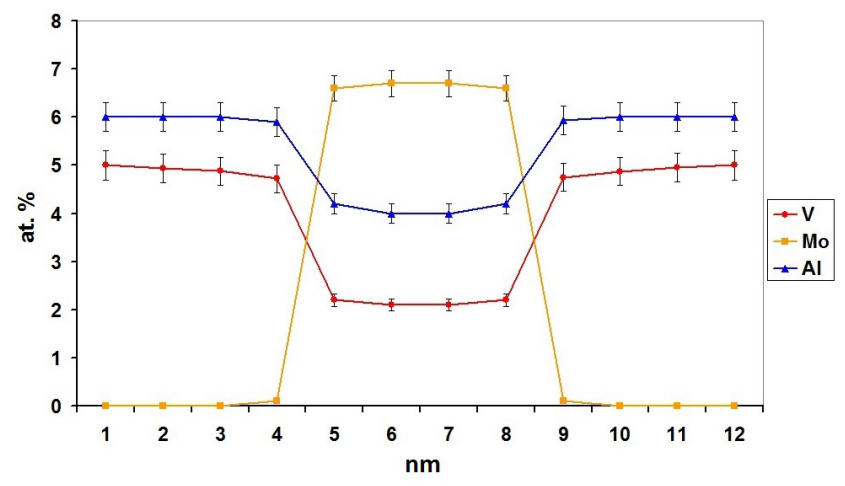

$\mathrm{b}$

Рис. 3. Микроструктура в зоне ТФС (a) и химический анализ в области границы соединения (b) после сварки давлением при температуре $T=700^{\circ} \mathrm{C}$.

Fig. 3. Microstructure SSJ zone (a) and chemical analysis of the zone of joining (b) after pressure welding at the temperature $T=700^{\circ} \mathrm{C}$.

при СД, регламентируя деформацию УМЗ прокладки. А при сварке давлением листовых заготовок из титанового сплава ВТ6 между собой без промежуточного листа наблюдается не большое расслоение по сварному соединению в зоне разрушения (рис. 4c). И только с увеличением дополнительного сварочного давления и времени выдержки в условиях низкотемпературной сверхпластичности возможно получить качественное ТФС.

По результатам фазового анализа титановых сплавов типа ВТ6 известно, что после нагрева и выдержки при температуре СП происходит заметное повышение количества объемно-центрированной кубической (ОЦК) $\beta$-фазы [7], которая обладает более высокой диффузионной проницаемостью, чем гексагональная плотноупакованная (ГПУ) $\alpha$-фаза, что и приводит к росту эффективного коэффициента диффузии сплава. Развитие ЗГП при СП деформации стимулирует диффузию по границам зерен и приводит к ускоренному залечиванию пор в зоне ТФС путем взаимного сдвига и раз- 


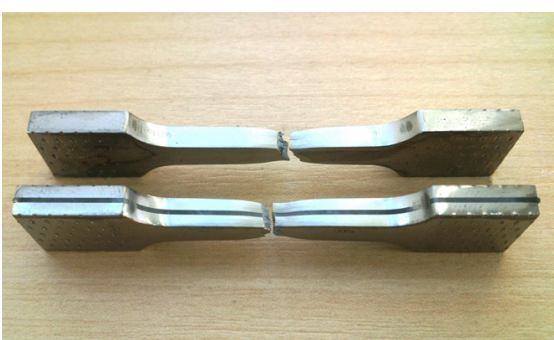

a

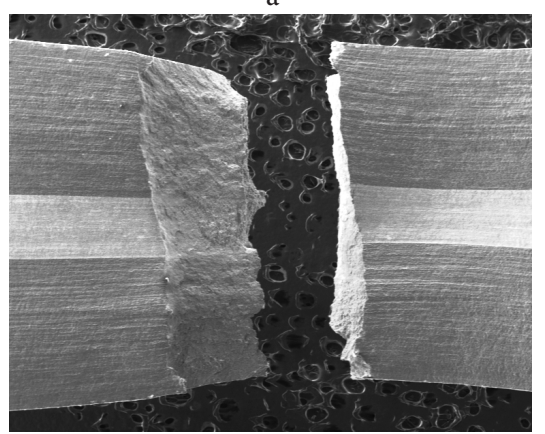

$\mathrm{b}$

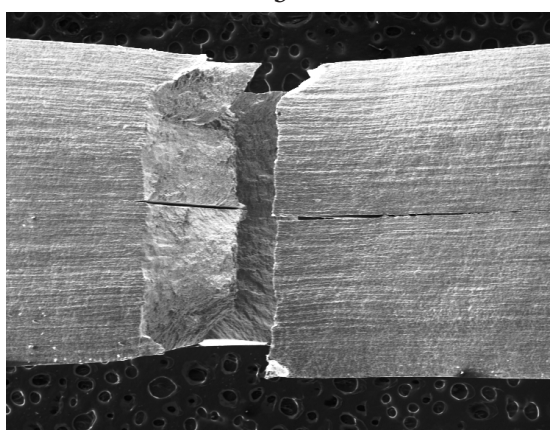

Рис. 4. Внешний вид поверхности разрушенного образца, соединенных между собой листов, после испытания на растяжение вдоль сварного соединения: а) общий вид; b) сварка c промежуточным листом; c) сварка без промежуточного листа.

Fig. 4. External view of the fracture surface, the specimen represented by welded sheets after the tensile test along the welded joint: a) general view; b) the welding with intermediate sheet; c) the welding without interlayer sheet.

ворота соседних зерен, которая, ускоряет процесс формирования ТФС. Кроме того, в двухфазном титановом сплаве ВТ6 $\beta$-фаза играет заметную роль в деформационном “залечивание” пор. В процессе СП деформации $\beta$-фаза являясь более пластичной, чем $\alpha$-фаза, проникая в полость вытянутых пор, разделяет на более мелкие и/или полностью заполняет их с увеличении степени деформации [8].

С уменьшением размера зерна в сплаве увеличивается суммарная протяженность их границ, что объективно обуславливает повышение доли ЗГП в процессе всей деформации [9].

Деформационные полосы способны перераспределяться в объеме материала, обеспечивая непрерывность течения при достаточном количестве зерен в поперечном сечении образца. Здесь одновременно действуют кооперированное ЗГП, деформация и вращение зерен, а также активно протекающие диффузионные процессы [10].

Результаты механических испытаний при комнатной температуре на растяжение и на сдвиг образцов, приведены в таблице 2 .

табл. 2. Результаты механических испытаний на растяжение и на сдвиг.

Table 2. The results of mechanical tests of tensile and shear tests.

\begin{tabular}{|c|c|c|c|c|c|}
\hline № & $\sigma_{0,2}, \mathrm{MPa}$ & $\sigma_{u t s}, \mathrm{MPa}$ & $\delta, \%$ & $\tau_{s h}, \mathrm{MPa}$ & Примечание \\
\hline 1 & 989 & 1007 & 17,2 & 528 & $\begin{array}{c}\text { Сварка без промежу- } \\
\text { точного листа } \\
\text { The welding without } \\
\text { interlayer sheet }\end{array}$ \\
\hline 2 & 1008 & 1025 & 19,4 & 649 & $\begin{array}{c}\text { Сварка с промежуточ- } \\
\text { ным листом } \\
\text { The welding with } \\
\text { interlayer sheet }\end{array}$ \\
\hline
\end{tabular}

Из таблицы 2 видно, что использование промежуточного листа из ВТ14 приводит к увеличению прочностных характеристик $\sigma_{u t s}, \tau_{\text {shear tests }}$ и при этом наблюдается небольшое повышение пластичности.

Как мы видим из экспериментальных данных, использование сплава ВТ14 в УМЗ исходном состоянии приводит к твердофазному соединению материалов при более низкой температуре в условиях низкотемпературной СП.

По результатам экспериментов заявлен способ сварки давлением заготовок из титанового сплава, включающий размещение между заготовками промежуточной прокладки из титанового сплава с исходным размером зерен менее 1 мкм и соединение заготовок и прокладки путем приложения давления к заготовкам, обеспечивающего соответствующую условиям сверхпластичности скорость деформации, в течение времени, достаточного для образования физического контакта между соединяемыми поверхностями заготовок и прокладки необходимых для развития объемного взаимодействия [11].

Таким образом, получение качественного твердофазного соединения различных титановых сплавов определяется не только размером зерен промежуточного листа, но и химическим и фазовым составом в зоне формирования сварного соединения.

Результаты проведенных экспериментов являются научной основой для разработки метода сварки давлением разнородных титановых сплавов для изготовления полой лопатки вентилятора для современного авиационного двигателя в условиях низкотемпературной сверхпластичности.

\section{4. Выводы}

Экспериментально показана возможность получения равнопрочного твердофазного соединения листов из промышленного титанового сплава ВТ6 при отно- 
сительно низкой температуре $\left(T=700^{\circ} \mathrm{C}\right)$ благодаря использованию промежуточного листа из ВТ14 с более мелком размером зерен $\sim 0,8$.

\section{Литература/References}

1. O. A. Kaybishev, R. Ya. Lutfullin, V.K. Berdin. Reports of the Academy of Sciences. (1991) Vol. 319, n 3, 615 p. (in Russian) [Кайбышев О.А., Лутфуллин Р.Я., Бердин В. К. ДАН. 1991. Т.319. № 3. С.615.]

2. R. Ya. Lutfullin, O.R. Valiakhmetov, R.M. Galeev, M.H. Muhametrahimov. Metals. (2002) no 2, 102p. (in Russian) [Лутфуллин Р.Я., Валиахметов О.Р., Галеев Р.М., Мухаметрахимов М.Х. Металлы. 2002. № 2. C.102.]

3. U.S. Tsvikker. Titanium and its alloys. Moscow, Metallurgy. (1979) 512 p. (in Russian) [Цвиккер У. Титан и его сплавы. М.: Металлургия, 1979. 512 с.]

4. I. V. Kazachkov, V.K. Berdin. Zavodskaja-laboratorija. 55 (7), $82-84$ (1989). (in Russian). [И.В. Казачков, В.К. Бердин. Заводская лаборатория 55 (7), 1989 С.
$82-84]$

5. V.K. Berdin, R. Ya. Lutfullin, I. V. Kazachkov. Sample of tensile test of metallic joint. Author certificate a1619112. (Bulletin of investigation a1, 1991) (in Russian) [В. К. Бердин, Р.Я. Лутфуллин, И.В. Казачков. Бюл. изобр. № 1,1991]

6. S.A. Saltukov. Stereometric Metallography, Metallurgia, Moscow, 1976, 271 p. (in Russian) [C.А. Салтыков. Стереометрическая металлография. // M.: Металлургия. 1976. 271 с.]

7. Kaybyshev O.A. The superplasticity of industrial alloys. Moscow, Metallurgy, 1984, 264 p. (in Russian). [Кайбы шев О.А. Сверхпластичность промышленных сплавов. М.: Металлургия, 1984. 264 с.]

8. R. Ya. Lutfullin, M. Kh. Mukhametrakhimov. Journal of Advanced Materials 7, 189 (2009) (in Russian).

9. O.A. Kaibyshev and R.Z. Valiev. Grain Boundaries and Properties of Metals, Metallurgia, Moscow, 1987, p.212. (in Russian)

10. В. В. Астанин. ФММ. т.79, вып. 3, с.166 - 172, 1995.

11. Patent №2415738, 2011. 